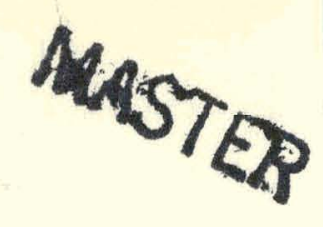

SPEX

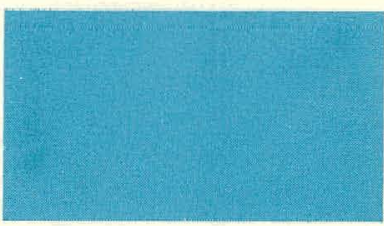

\title{
COMPARISON OF COMPUTED CENTERLINE DOSE RATES FROM DIFFERENT AREAS OF A SOURCE PLATE
}

\author{
A.W. CASPER \\ J.G. CARVER
}




\section{DISCLAIMER}

This report was prepared as an account of work sponsored by an agency of the United States Government. Neither the United States Government nor any agency Thereof, nor any of their employees, makes any warranty, express or implied, or assumes any legal liability or responsibility for the accuracy, completeness, or usefulness of any information, apparatus, product, or process disclosed, or represents that its use would not infringe privately owned rights. Reference herein to any specific commercial product, process, or service by trade name, trademark, manufacturer, or otherwise does not necessarily constitute or imply its endorsement, recommendation, or favoring by the United States Government or any agency thereof. The views and opinions of authors expressed herein do not necessarily state or reflect those of the United States Government or any agency thereof. 


\section{DISCLAIMER}

Portions of this document may be illegible in electronic image products. Images are produced from the best available original document. 


\section{LEGAL NOTICE}

This report was prepared as an account of Government sponsored work. Neither the United States, nor the Commission, nor any person acting on behalf of the Commission:

A. Makes any warranty or representation, expressed or implied, with respect to the accuracy, completeness, or usefulness of the information contained in this report, or that the use of any information, apparatus, method, or process disclosed in this report may not infringe privately owned rights; or

B. Assumes any liabilities with respect to the use of, or for damages resulting from the use of any information, apparatus, method, or process disclosed in this report.

As used in the above, "person acting on behalf of the Commission" includes any emplnyee or contractor of the Commission, or employee of such contractor, to the extent that such employee or contractor of the Commission, or employee of such contractor prepares, disseminates, or provides access to, any information pursuant to his employment of cuntsact with the Commission, or his employment with such contractor.

Printed in USA. Price $\$ 1.00$. Available from the

Offlce of Technical Services

U.S. Department of Commerce Washington 25, D.C. 


\section{COMPARISON OF COMPUTED CENTERLINE DOSE RATES FROM DIFFERENT AREAS OF A SOURCE PLATE}

A. W. CASPER

J. G. CARVER

Nuclear Development Laboratories Sub-Section

November 1958

United States Air Force

United States Atomic Energy Commission
Contract No. AF 33(600)-38062

Contract No. AT (11-1)-171

\footnotetext{
GENERAL ELECTRIC

ATOMIC PRODUCTS DIVISION AIRCRAFT NUCLEAR PROPULSION DEPARTMENT

Cincinnati 15, Ohio
}

Published by

Technical Publications Sub-Section

August 1959 


\begin{abstract}
A shield fixture that consists of a slab of iron with a cylindrical hole into which plugs of various materials can be inserted is described. Computations made to determine the effect of source-plate size on centerline dose rates are described, and incremental dose contributions from variuus annular sections of the source plate are presented. Plugs of iron, aluminum, andlead were used in the computations.
\end{abstract}




\section{Introduction}

Under the terms of a sponsor agreement with the General Electric Aircraft Nuclear Propulsion Department, the Battelle Memorial Institute has constructed at its West Jefferson, Ohio, reactor site a fission-plate facility for shielding studies of interest to GE-ANPD. This facility ${ }^{1}$ is similar in general design to the Lid Tank Facility ${ }^{2}$ at Oak Ridge National Laboratory. Its general features are displayed in Figures 1 and 2.

One type of shielding experiment to be performed in this facility is designed to determine fastneutron-attenuation properties of new shielding materials through measurements made on moderately small cylindrical samples of such materials. A 4-foot-square iron plate, 13.65 centimeters thick, is provided with a cylindrical hole into which the sample fits. The plate with its sample is then positioned in front of the source plate, and measurements are made in water behind the plate. Because of its high fast neutron removal cross section $\left(0.168 \mathrm{~cm}^{-1}\right)$, iron was chosen as the containing plate in order to maximize the effect of the sample material upon the measured dose rates.

To interpret the measurements, it is necessary to be able to estimate the relative contributions of different areas of the source plate (and, by inference, the neutrons which pass through the iron or the sample, respectively) to the dose rate at a given point in the water behind the array. The present study was carried out to provide such information. Inasmuch as the computer program used furnishes the gamma ray dose rates at very little additional cost, the study was extended to include them.

The results of the computations are presented in four distinct groups:

1. The centerline dose rates for various source-plate radii.

2. The centerline dose rates from various annular zones of the source plate

3. The ratios of the dose rates in (1.) to the full-plate dose rates.

4. The dose rate contributions, per square centimeter of source-plate area, averaged over the same annular regions considered in (2.)

Throughout the study it was assumed that a given unit area of the source plate either operated at a given constant power or was inoperative. A given annular ring, for example, was either considered as "turned off" or as operating at its particular fixed power. These power density (watts $/ \mathrm{cm}^{2}$ ) values were so chosen to give a total power of 1 watt for the complete source plate in operation. 


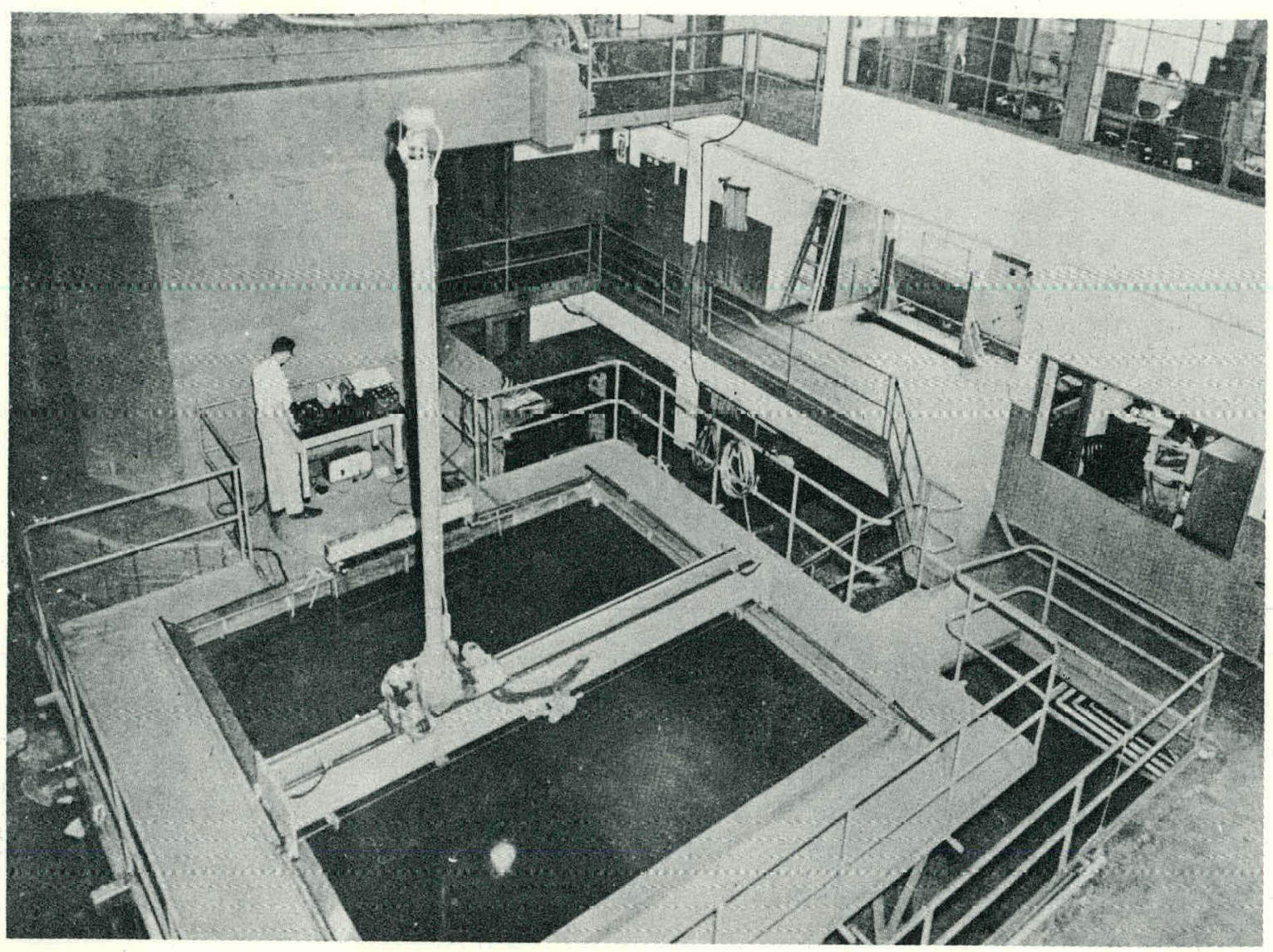

Fig. 1 -Shielding-research area 


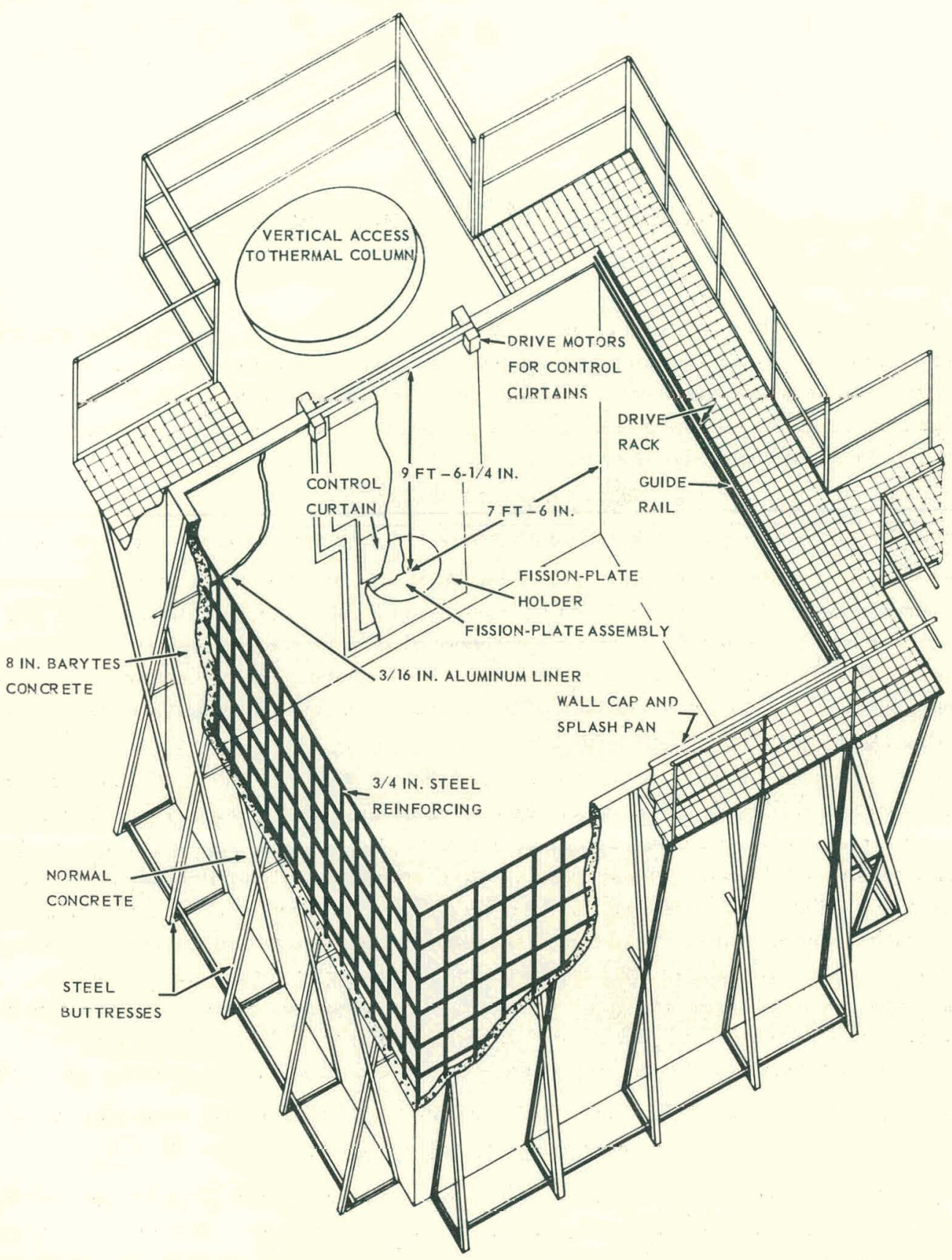

Fig. 2-Tank for shielding facility 


\section{Description of the Computations}

The fission source was assumed to be a disk. Table 1 gives the assumed gamma ray source strength for each 1-Mev energy interval considered. Gamma sources outside the source plate were replaced by equivalent sources within the source plate. The source-plate power was as sumed to vary radially in the same manner as the following cosine function used to describe the radial variation of thermal neutron flux incident upon the source plate.

$$
S(R)=3.012 \times 10^{-4} \cos 0.0232 \mathrm{R}
$$

This function gives a value of 1 watt of power for a full source-plate radius of 35.56 centimeters.

The active area of the source plate can be varied by use of a boral iris. In these calculations it was assumed that the boral iris produced a "clean" cutoff of power at a fixed radius, and six values of this radius between 9 and 35.56 centimeters were chosen for the computations. The arrangement of materials is indicated in Figure 3. Cylindrical symmetry about the centerline is assumed. The composition, density, and cross sections of the mixture of materials, which was used to represent the source-plate assembly, are given in Table 2.

Dose rate computations were made at seven detector points along the centerline. The point kernel approach, used in this study, is based on the computation of the attenuation introduced in the passage of radiation from a point source to a point detector. The point kernel approach is applied to planedistributed sources by treating the source as a distribution of source points having appropriate strength, computing the radiation flux incident on the detector from each point source, and finally, integrating over the entire source area to obtain the total radiation flux incident on the detector. Most of the complexity of the calculation arises from the large number of simple computations required to determine the distances traversed in each material encountered between the source and detector points, particularly when the shield geometry is of any but the simplest type. The ANP Department has developed digital computer program 04-2 for carrying through such computations for cylindrically symmetric cases. ${ }^{3}$

The gamma ray point kernel is of the type illustrated by the following expression for attenuation:

$$
\Psi\left(E_{j}\right)=B\left(X_{1}, X_{2}, E_{j}\right) \exp [-\Sigma(\mu t)]
$$

where $\Psi\left(E_{j}\right)$ is the attenuation of gamma rays of the $j$-th energy group; $\Sigma(\mu t)$ represents the sum of the relaxation lengths in the path; $B\left(X_{1}, X_{2}, E_{j}\right)$ is the buildup factor computed for two successive materials (or types of material); $\mathrm{X}_{1}$ is the sum of the relaxation lengths encountered in those materials assumed to contribute scattered radiation according to the buildup factor for the first material encountered; and $\mathrm{X}_{2}$ is a similar sum of relaxation lengths for the last material (or group of mutually similar materials) encountered.

The following combination of single-material buildup factors, developed by M. H. Kalos, was employed for the case where the high- $Z$ material (lead) was followed by materials such as water:

$$
B\left(X_{1}, X_{2}, E_{j}\right)=B_{2}\left(X_{2}\right)+\left[\frac{B_{1}\left(X_{1}\right)-1}{B_{2}\left(X_{1}\right)-1}\right] \quad\left[B_{2}\left(X_{1}+X_{2}\right)-B_{2}\left(X_{2}\right)\right]
$$

where the subscripts 1 and 2 refer to the two buildup factors (and corresponding materials) represented. In the case of iron followed by materials like water, simple iron buildup was us ed. In the case of aluminum followed by water, simple water buildup was used. 
TABLE 1

GAMMA RAY SOURCE STRENGTH

(Mev/w-sec)

\begin{tabular}{|c|c|c|c|c|c|c|c|}
\hline $\mathrm{E}, \mathrm{Mev}$ & $\begin{array}{l}\text { Prompt } \\
\text { Fission } \\
\text { Gammas }\end{array}$ & $\begin{array}{l}\text { Fissiun } \\
\text { Product } \\
\text { Gammas }\end{array}$ & $\begin{array}{c}\mathrm{U}^{235} \\
\text { Capture } \\
\text { Gammas }\end{array}$ & $\begin{array}{l}\text { Equivalent } \\
\text { B }^{10} \text { Source } \\
\text { of Gammas }\end{array}$ & $\begin{array}{c}\text { Thermal } \\
\text { Column } \\
\text { Al Captures }\end{array}$ & $\begin{array}{c}\mathrm{Ni} \\
\text { Capture } \\
\text { Gammas }\end{array}$ & Total \\
\hline 0.5 & 7.426 & 5.583 & 1. 097 & 0.2092 & 0.0717 & 0.0001 & 14.387 \\
\hline 1.5 & 8. 361 & 5.363 & 1.235 & & 0.0975 & 0.0001 & 15.057 \\
\hline 2.5 & 4. 561 & 2.975 & 0.6736 & 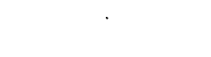 & 0.2556 & 0.0001 & 8.465 \\
\hline 3.5 & 2.258 & 1.219 & 0.3335 & & 0.2372 & 0.0004 & 4. 048 \\
\hline 4.5 & 1.164 & 0.3153 & 0.1719 & & 0.2372 & 0.001 & 1. 889 \\
\hline 5.5 & 0.6138 & 0.0663 & 0.09066 & & 0.0938 & 0.0015 & 0.8661 \\
\hline 6.5 & 0.3174 & 0.0126 & 0.04688 & & 0.0772 & 0.0025 & 0.4566 \\
\hline 7.5 & 0.1152 & 0. 0024 & 0.01702 & & 0.3494 & 0.0026 & 0.4866 \\
\hline 8.5 & 0.0264 & 0.00045 & 0.00389 & & 0 & 0.0087 & 0.0394 \\
\hline 9.5 & 0.0048 & 0.00008 & 0.000709 & & 0 & 0.0019 & 0.00749 \\
\hline
\end{tabular}

${ }^{a}$ Multiply all source strengths by $10^{10}$. 
TABLE 2

DATA ON MIXTURE OF MATERIALS USED TO REPRESENT THE SOURCE-PLATE ASSEMBLY

Linear Gamma Ray Total Absorption Coefficients for the Mixture

\begin{tabular}{cc}
\hline E, Mev & $\sum, \mathrm{cm}^{-1}$ \\
\hline 0.5 & 0.2702 \\
1.5 & 0.1406 \\
2.5 & 0.1087 \\
3.5 & 0.0951 \\
4.5 & 0.0868 \\
5.5 & 0.0827 \\
0.5 & 0.0804 \\
7.5 & 0.0783 \\
8.5 & 0.0766 \\
9.5 & 0.0754 \\
\hline
\end{tabular}

Fast Neutron Cross Section for the Mixture

$$
\Sigma=0.0769 \mathrm{~cm}^{-1}
$$

Density of the Mixture

$$
\rho=2.786 \mathrm{~g} / \mathrm{cm}^{3}
$$

Compusition of the Mixture

\begin{tabular}{cc}
\hline Materials & Volume Fraction \\
\hline $\mathrm{Al}$ & 0.8169 \\
$\mathrm{U}^{235}$ & 0.0214 \\
Void & 0.0858 \\
$\mathrm{~B}_{4} \mathrm{C}$ & 0.075 \\
$\mathrm{Ni}$ & 0.0009 \\
\hline
\end{tabular}




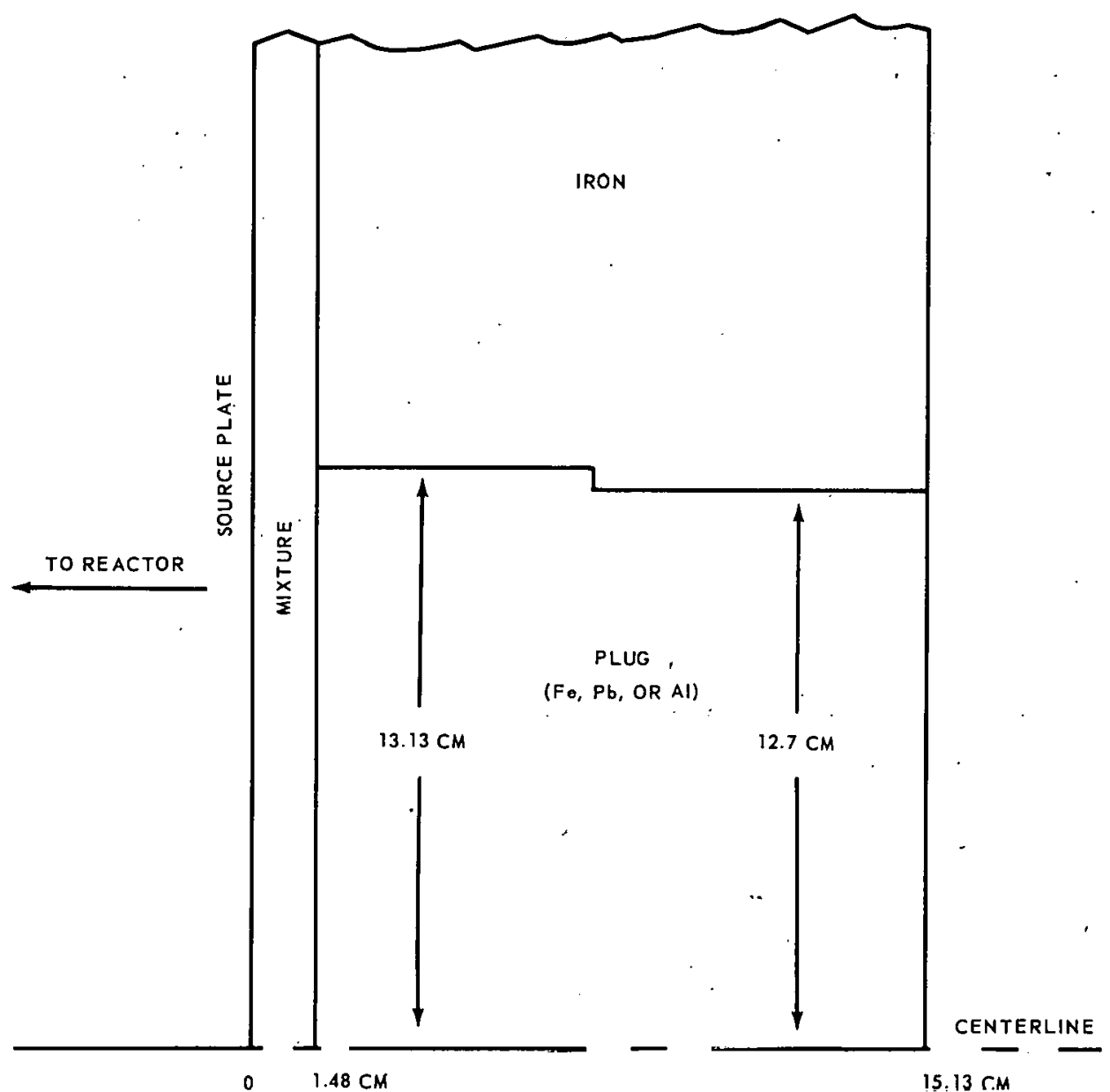

Fig, 3-Vertical section through souree-plate centerline 
The total gamma ray energy flux at a given point is then computed as

$$
\phi_{\gamma}=\sum_{j=1}^{J} \frac{\mathrm{CB}_{j}}{4 \pi} \int \mathrm{r} \mathrm{p}(\mathrm{r}) \mathrm{dr} \int \frac{\Psi\left(\mathrm{E}_{\mathrm{j}}\right)}{\rho^{2}} \mathrm{~d} \phi
$$

where the integration is carried out over the entire area of the active source plate. The summation indicated is over energy groups (of which 10 were used here), $B_{j}$ is the source strength for the $j$-th energy group in $\mathrm{Mev} / \mathrm{cm}^{2}$-watt at the point of maximum power in the source plate, $p(r)$ is a function describing the radial power distribution in the source plate, $\rho$ is the distance between source and detector points, and $\Psi$ has the form given in equation (2).

The fast neutron dose rates were computed according to the same procedure as that described above for gamma rays, with the exception that a different point-kernel was employed. The point attenuation kernel used is a modification of that suggested by Albert and Welton and is of the form

$$
\Psi=a_{1}\left(\eta t^{\prime}\right)^{a_{2}} \exp \left[-a_{3}\left(\eta t^{\prime}\right)^{a_{4}}-\sum_{m}\left(\Sigma_{n t m} t_{m}\right)\right]
$$

where

$a_{1}=7.29 \times 10^{9}$ for $\Psi$ in units of mrep $/ \mathrm{hr}-\mathrm{w}$

$a_{2}=0.29$

$a_{3}=0.83$

$a_{4}=0.58$

$\Sigma_{n \text { rm }}$, fast neutron removal cross section of material $m$

$t$, thickness of material $\mathrm{m}$

$\sum_{m}$, summation over all nonhydrogenous materials encountered

$\mathbf{t}^{\prime}$, thickness of hydrogenous backing material

$\eta$, ratio of hydrogen atom density in hydrogenous material to that of water .

The total dose is computed by substituting equation (5) for equation (2) in the integral of equation (4).

In the actual computer program the puvduct $4 c^{\prime}$ is taleen ao the rum of the individual products of this type for each of the hydrogenous materials preselt. (In ule piesint study watur was the nnly hydrngenous material present.) Equation ( 5 ) is not energy-dependent since the derivation of this function includes an integration over the fission neutron energy spectrum.

Plugs of iron, aluminum, and lead fit into the hole in the iron slab. Aluminum was selected because it has a lower atomic weight than iron, and lead because it has a higher atomic weight than iron. The step in the radius of the plug prevents streaming. 


\section{Results of the Computations}

Samma ray dose rares as a function of distance from the center of the fission plate along the centerline, with the iron plug in place, are shown in Figure 4. A curve is plotted for each value of source radius under the assumption that each element of area of the plate that is not shielded by the boral iris receives the same thermal neutron flux as it does when the iris is removed and that the total source-plate power in the absence of an iris is 1 watt. The 9-centimeter source-plate radius is smaller than the plug radius and gives rise to the indicated attenuation curve. The top line represents the results obtained when the whole source plate of 35.56 centimeters radius is operating at a power of 1 watt. The dose rate changes more rapidly with radius of the source plate when the distance, $Z$, from the source plate is large.

Gamma dose rates as a function of distance along the centerline with the aluminum plug in place are shown in Figure 5. Changes in the source-plate radius make very small differences in dose rate when the source-plate radius exceeds the radius of the aluminum plug.

Gamma dose rates as a function of distance along the centerline with the lead plug in place are shown in Figure 6. Large changes in gamma dose result when the source radius is changed. With the 35.56-centimeter source-plate radius the dose curve has a maximum point. This does not occur in the cases where iron and aluminum plugs were used.

Fast neutron dose rates as a function of distance along the centerline are shown in Figures 7 , 8 , and 9. A curve is plotted in Figure 7 for each value of the source radius when the iron plug is placed in the iron slab. Figure 8 shows a similar set of curves for the aluminum plug, and Figure 9 shows the set of curves for the lead plug. The top curve in each figure represents the results when the whole source plate of 35.56 centimeters radius is operating at a power of 1 watt. As the sourceplate radius is reduced, the power is reduced a corresponding amount. The magnitude of the dose changes with the size of the source plate in all cases, but the shapes of the curves are changed very little.

Gamma dose contributions from various annular regions in the source plate as a function of distance along the centerline are given in Figures 10,11, and 12. The radii of the circles that bound the annular regions are given on the graph of each curve. The curves in Figures 10, 11, and 12 were obrained when the iron plug, aluminum plug, and lead plug were used in the iron slab, respectively.

In the three cases when the source is the 9-centimeter-radius disk, the gamma dose is a continuously decreasing function. When the source is the annular region of largest radius, the gamma dose function has a maximum point. In the case of the alunininum plug, the gamma dose funetion associated with the annular source region of largest radius has a maximum point and a minimum point. In all of these curves it is assumed that the annular region in question is cxposed to the same thermal neutron flux which it receives when no iris is present, and when the total source-plate power is 1 watt.

Neutron dose contributions from various annular regions in the source plate are given in Figures 13,14 , and 15 as functions of distance along the centerline. The radii of the circles that bound the annular regions are given in the graph of each curve. The curves in Figures 13,14, and 15 were obtained when the iron plug, aluminum plug, and lead plug were used in the iron slab, respectively. 


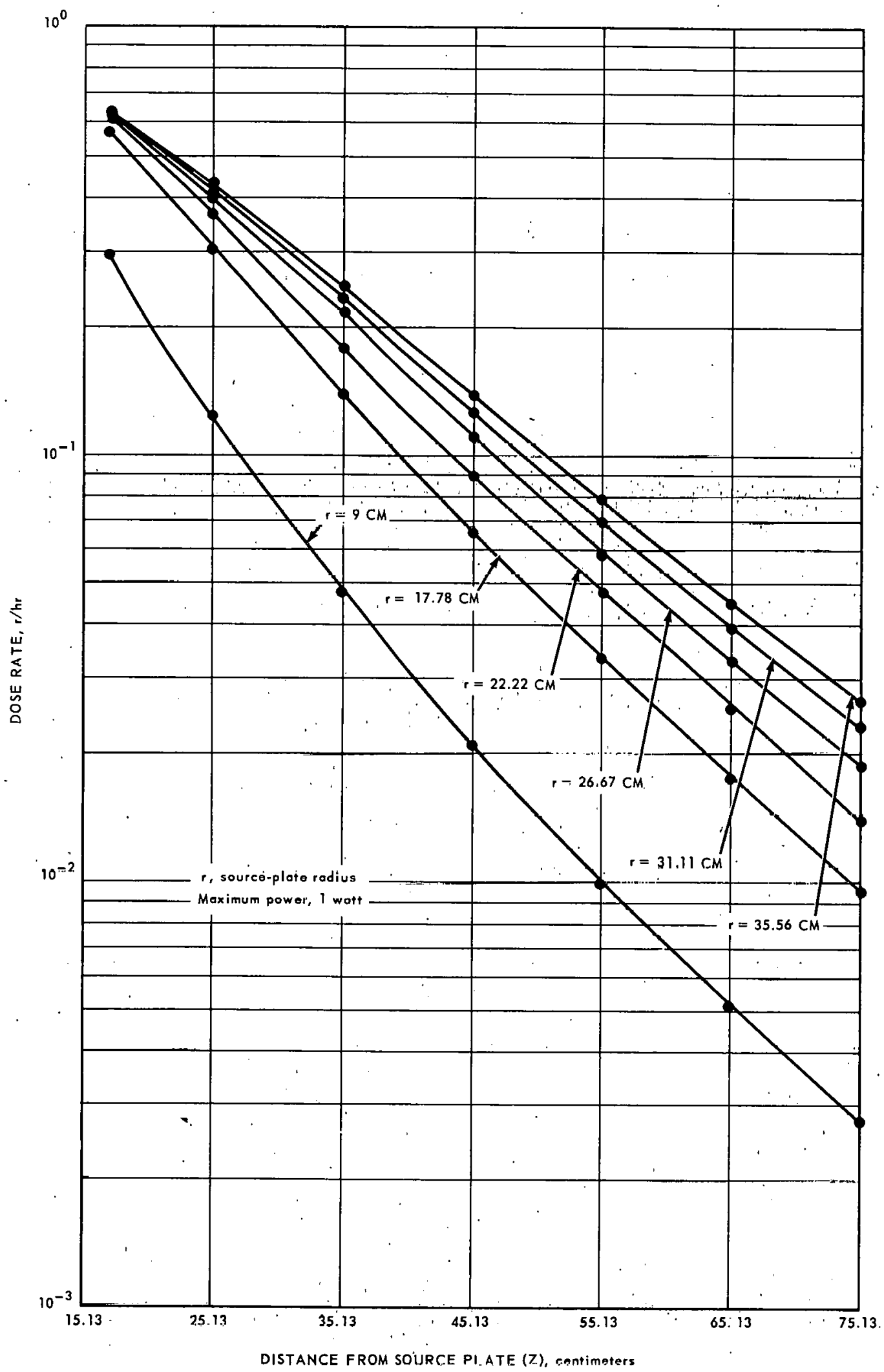

Fig. 4-Centerline gamma ray dose rate for various source-plate radii with iron plug inserted 


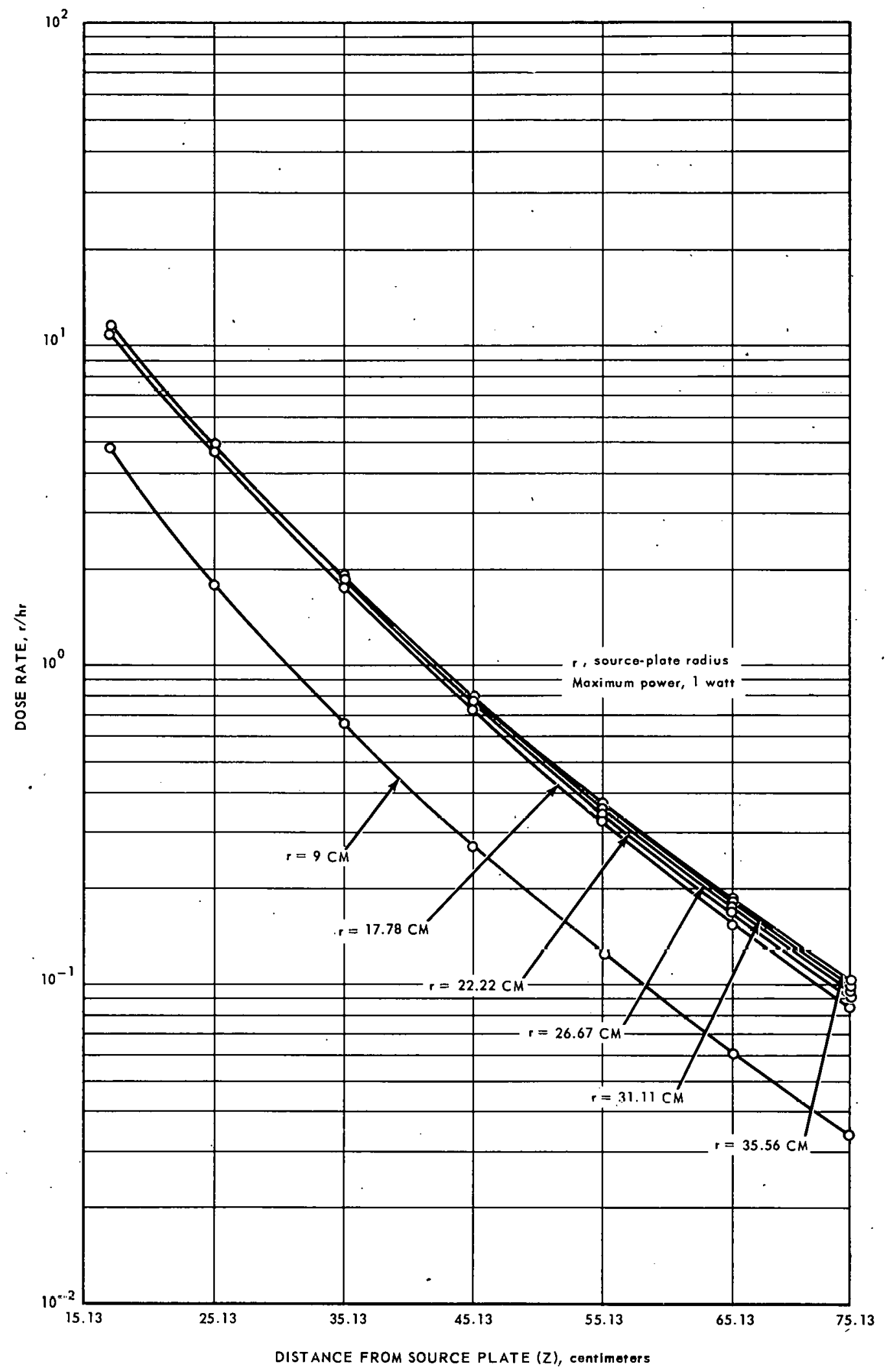

Fig. 5 - Centerline gamma ray dose rate for various source-plate radii with aluminum plug inserted 


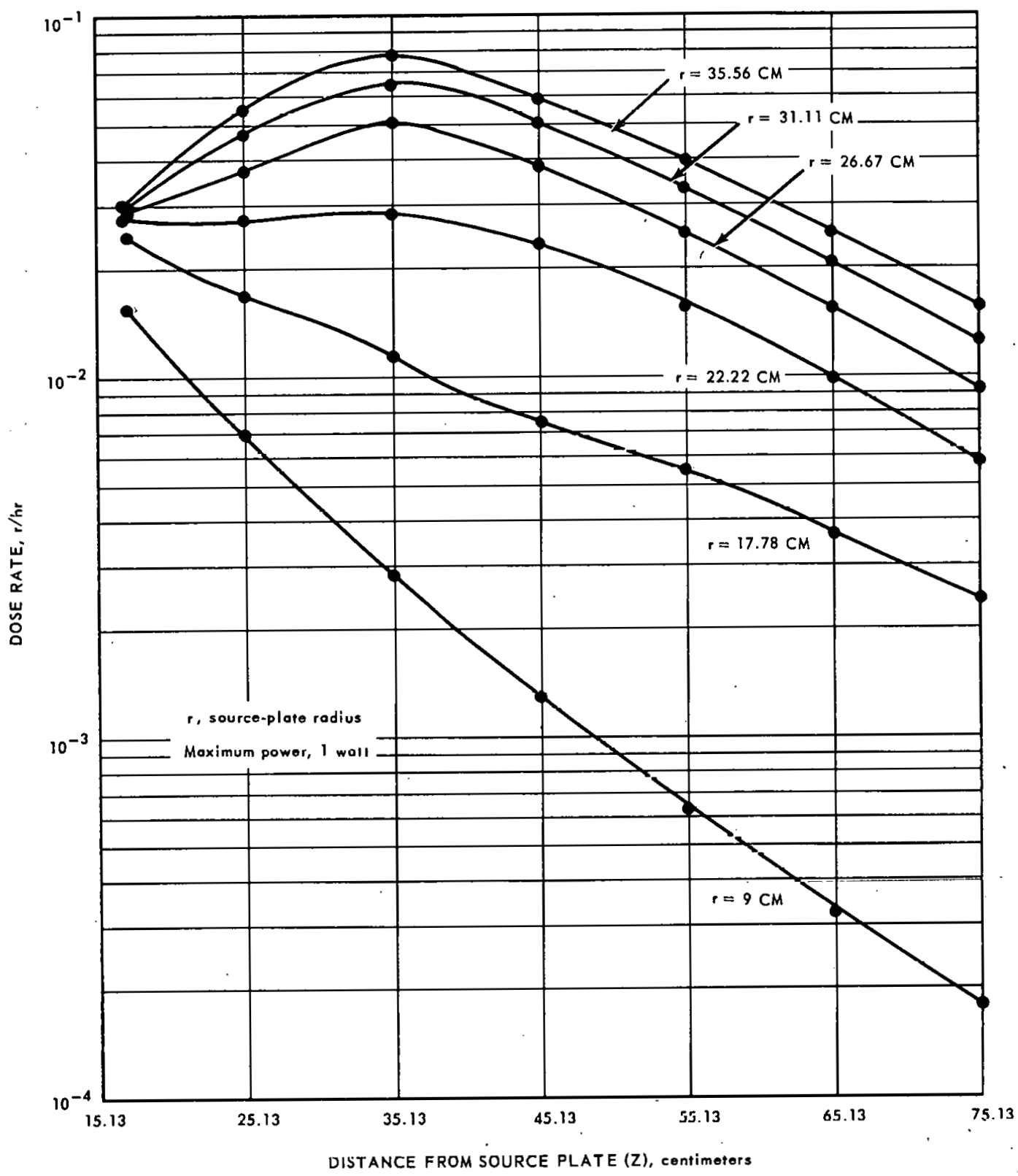

Fig.6-Centerline gamma roy dose rate for various source-plote radii with lead plug inserted 


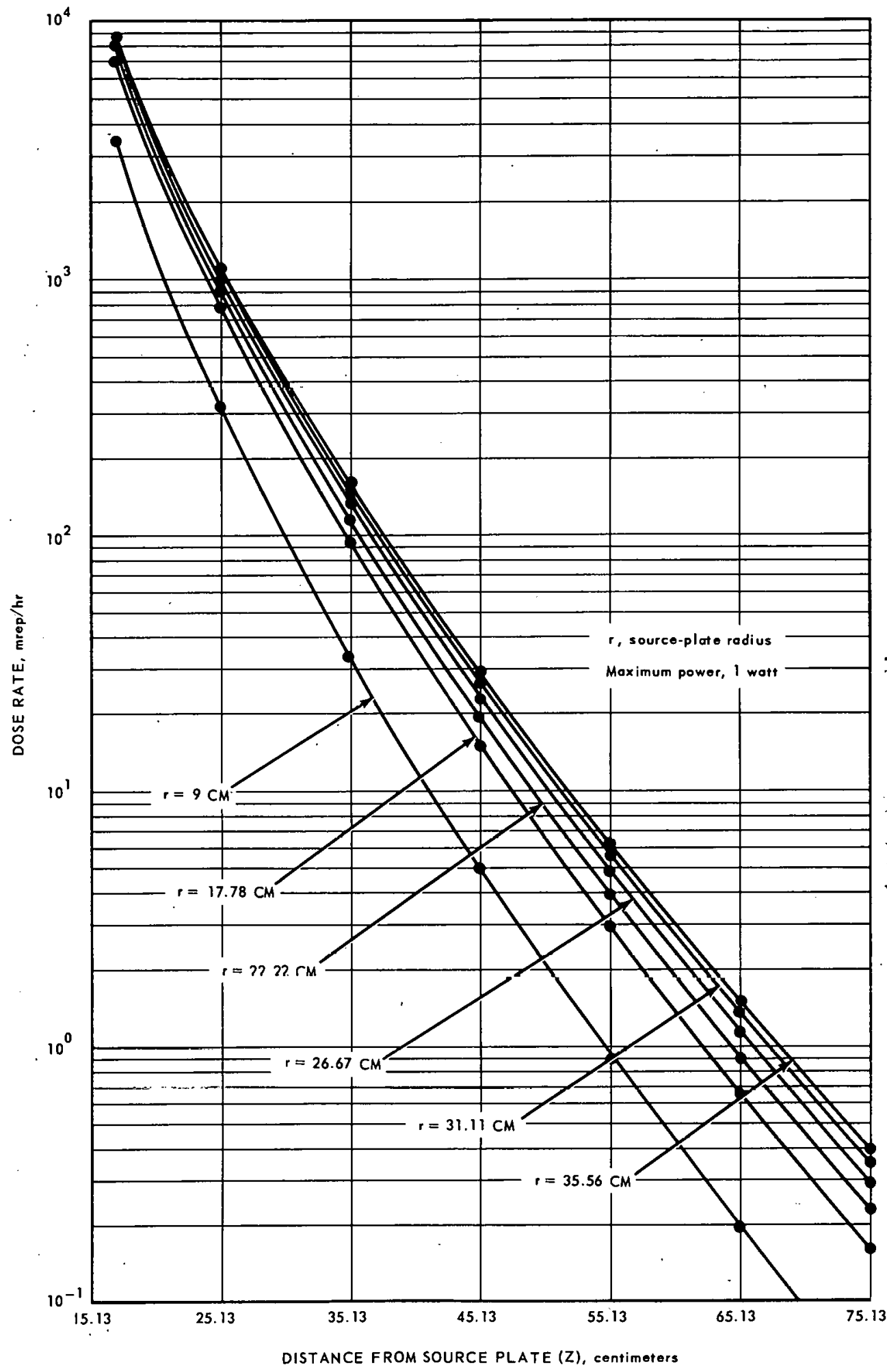

Fig. 7 - Centerline neutron dose rate for various source-plate rodii with iron plug inserted 


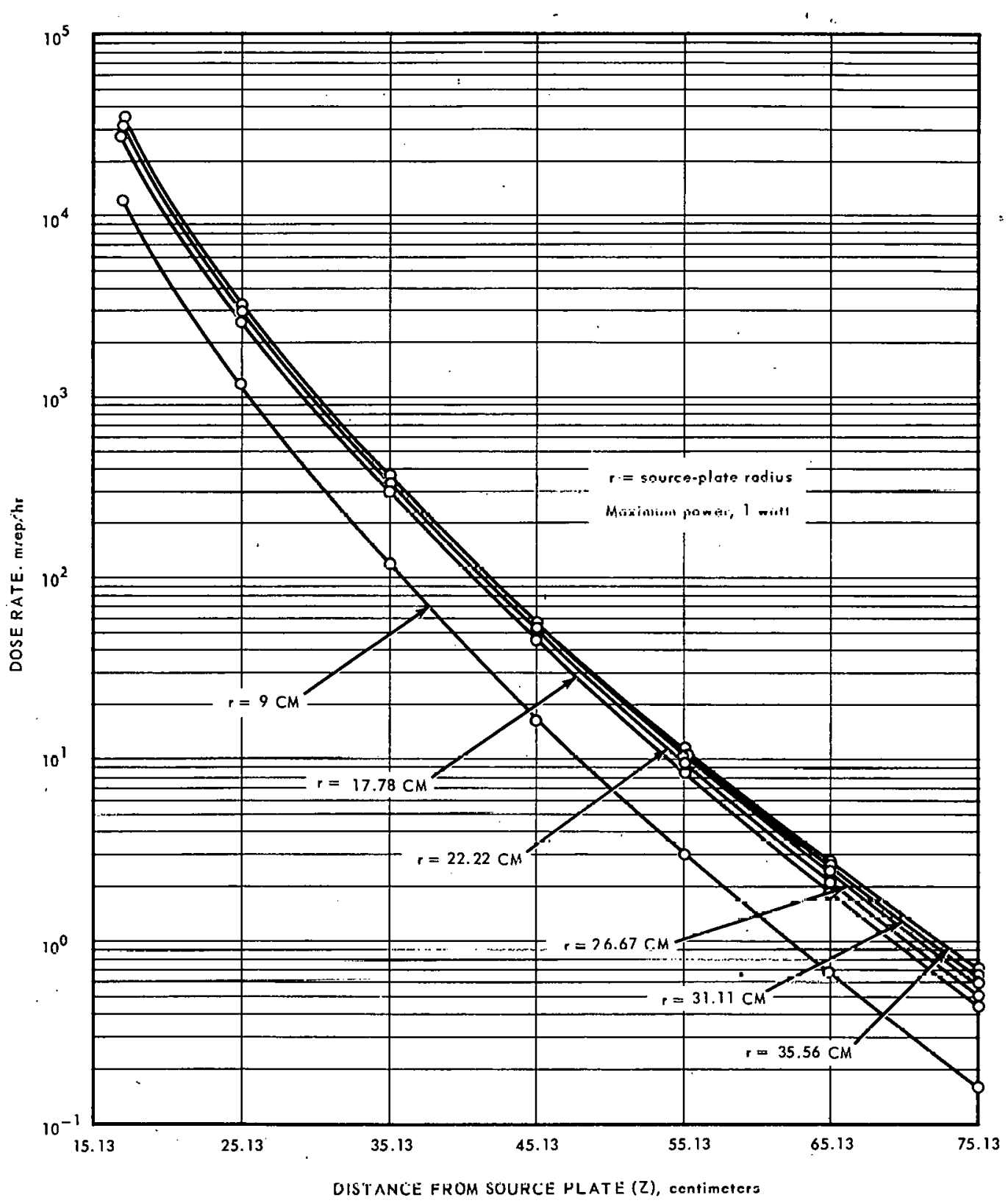

Fig. 8 - Centerline neutron dose rate for various source -plate radii with aluminum plug inserted 


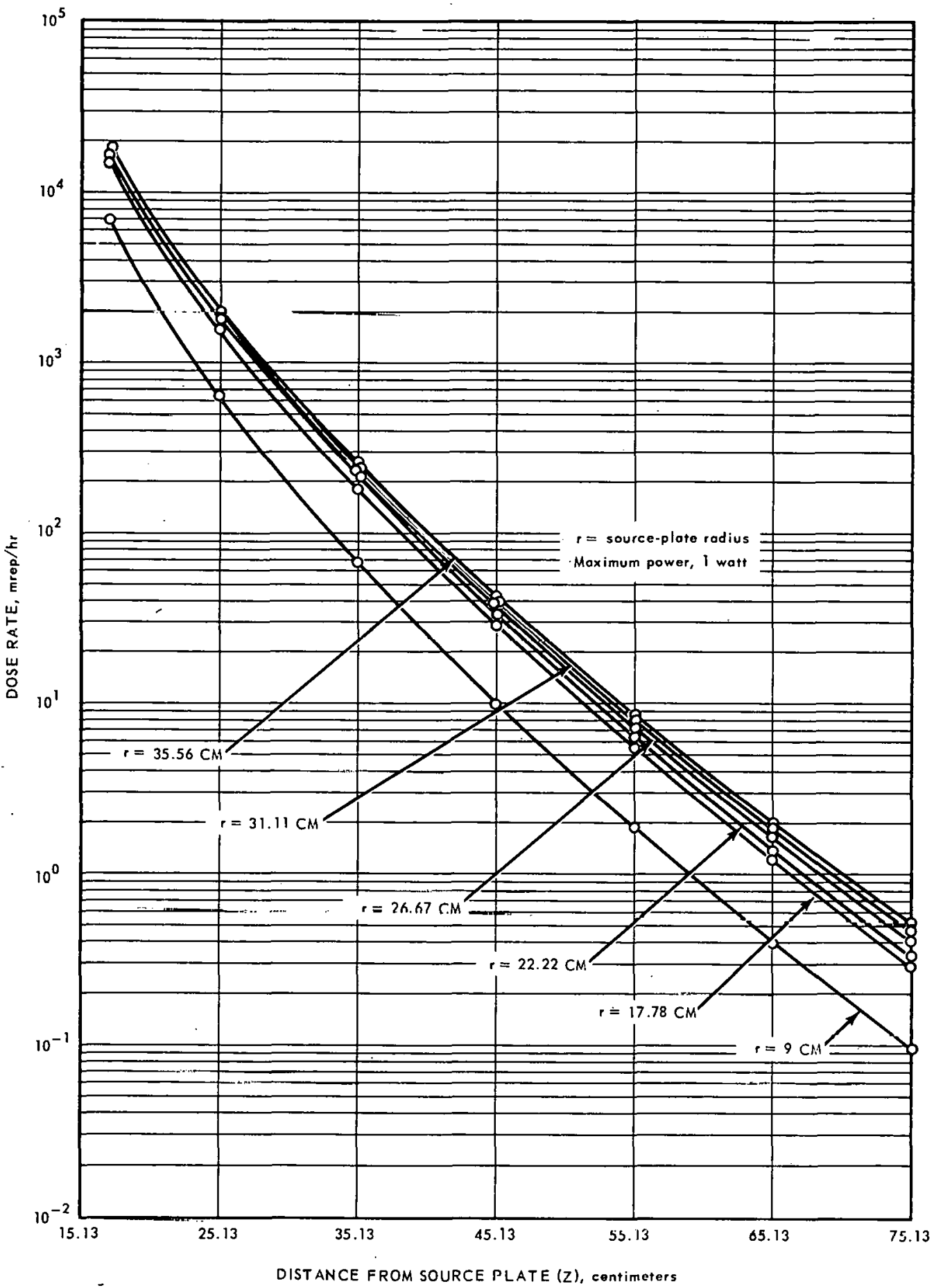

Fig. 9 - Centerline neutron dose rate for various source-plate radii with loodplug inserted 


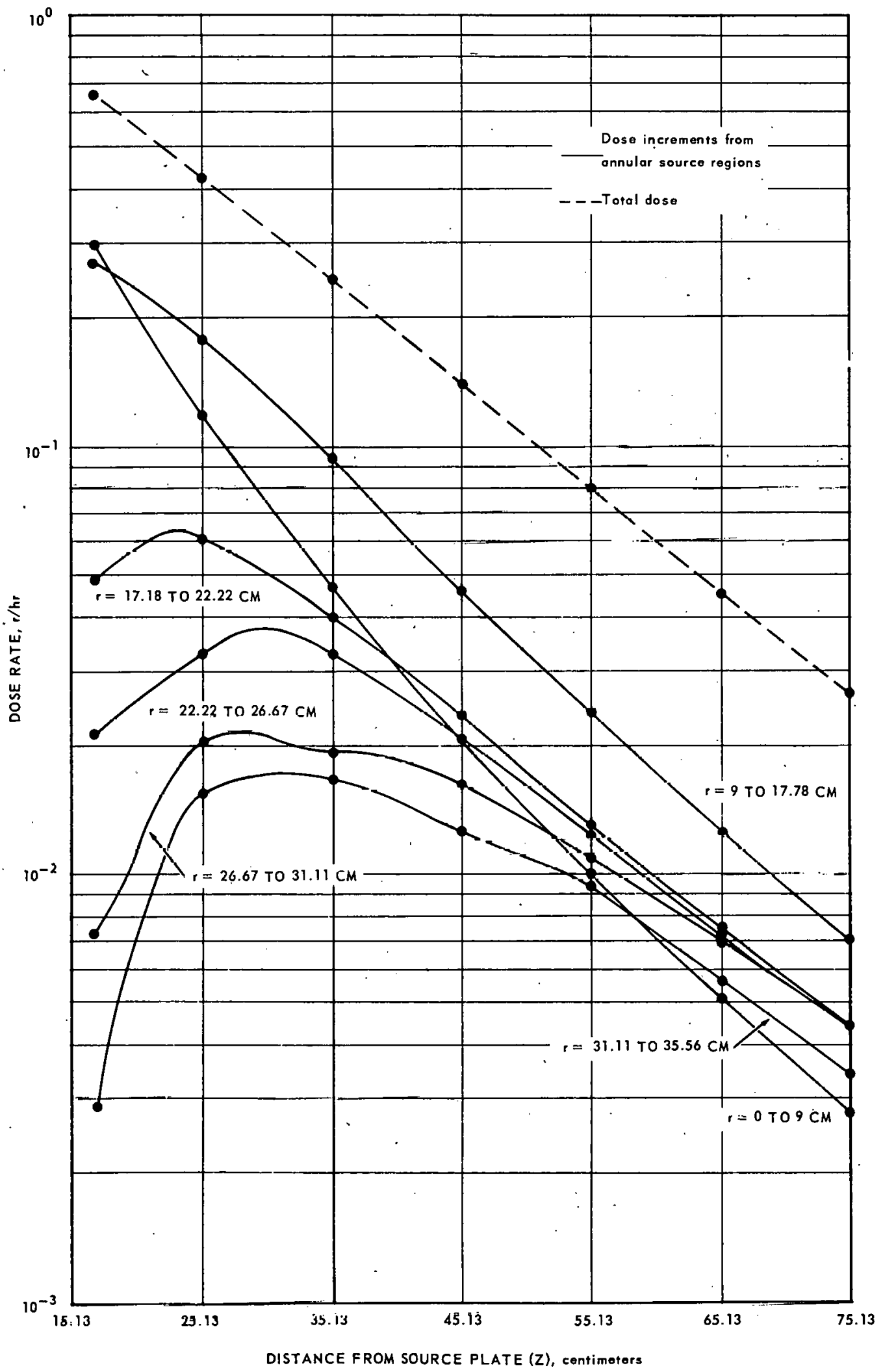

Fig. 10 - Centerline gamma ray dose rates from individual annular regions with iron plug inserted 


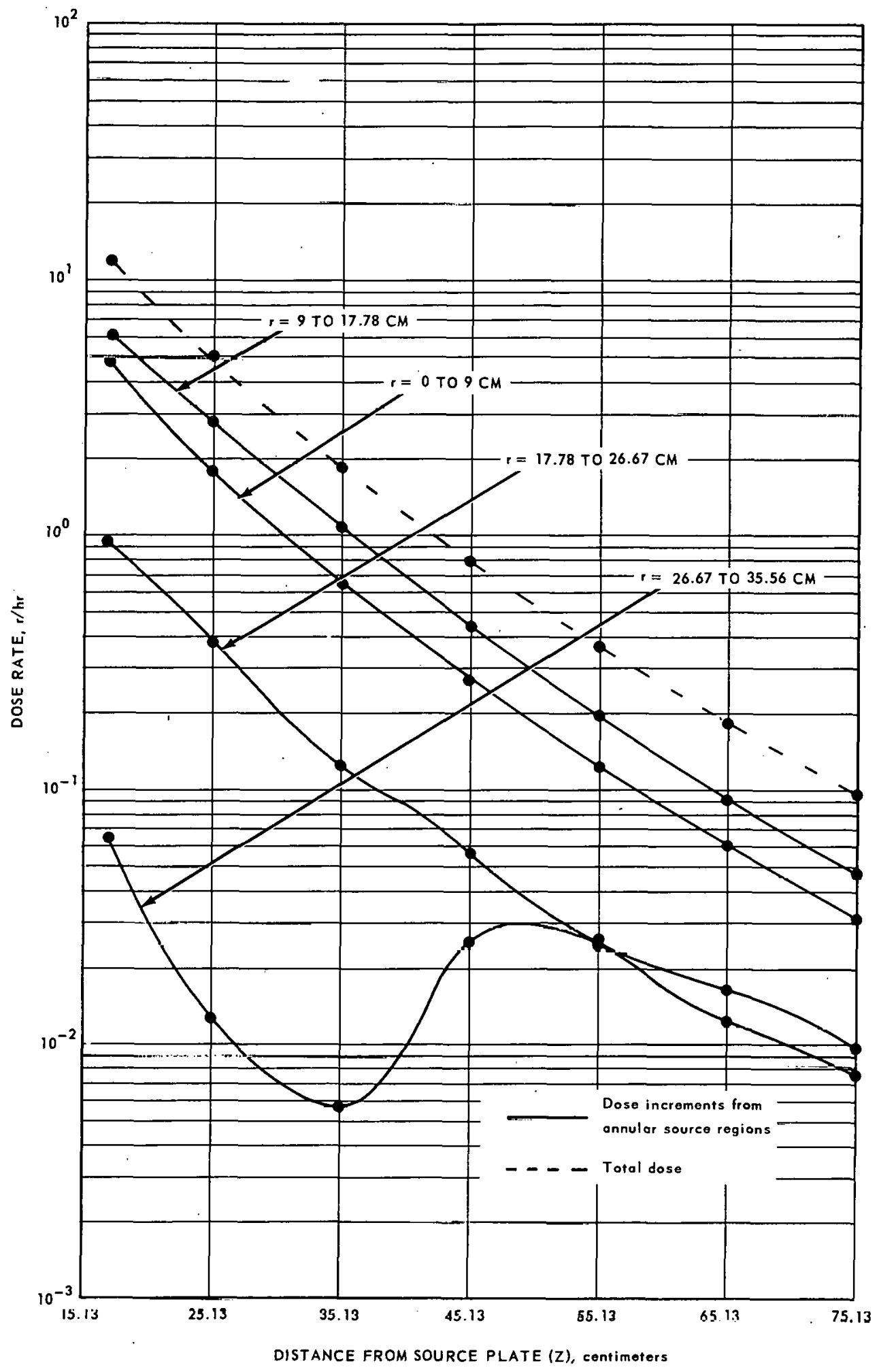

Fig. 11 - Centerline gamma ray dose rates from individual annular regions with aluminum plug inserted 


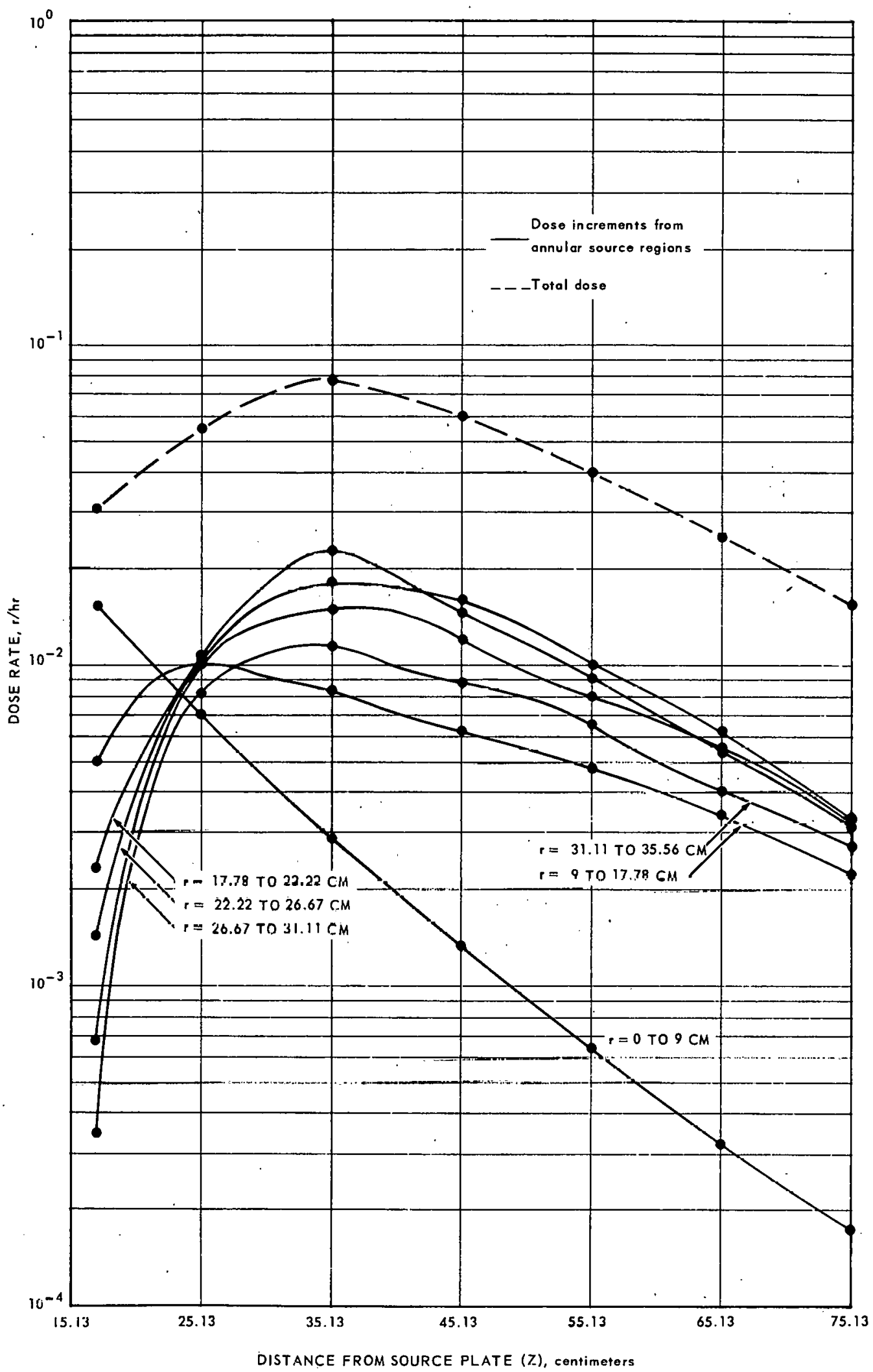

Fig. 12 - Centerline gamma ray dose rates from individual annular regions with lead plug inserted 


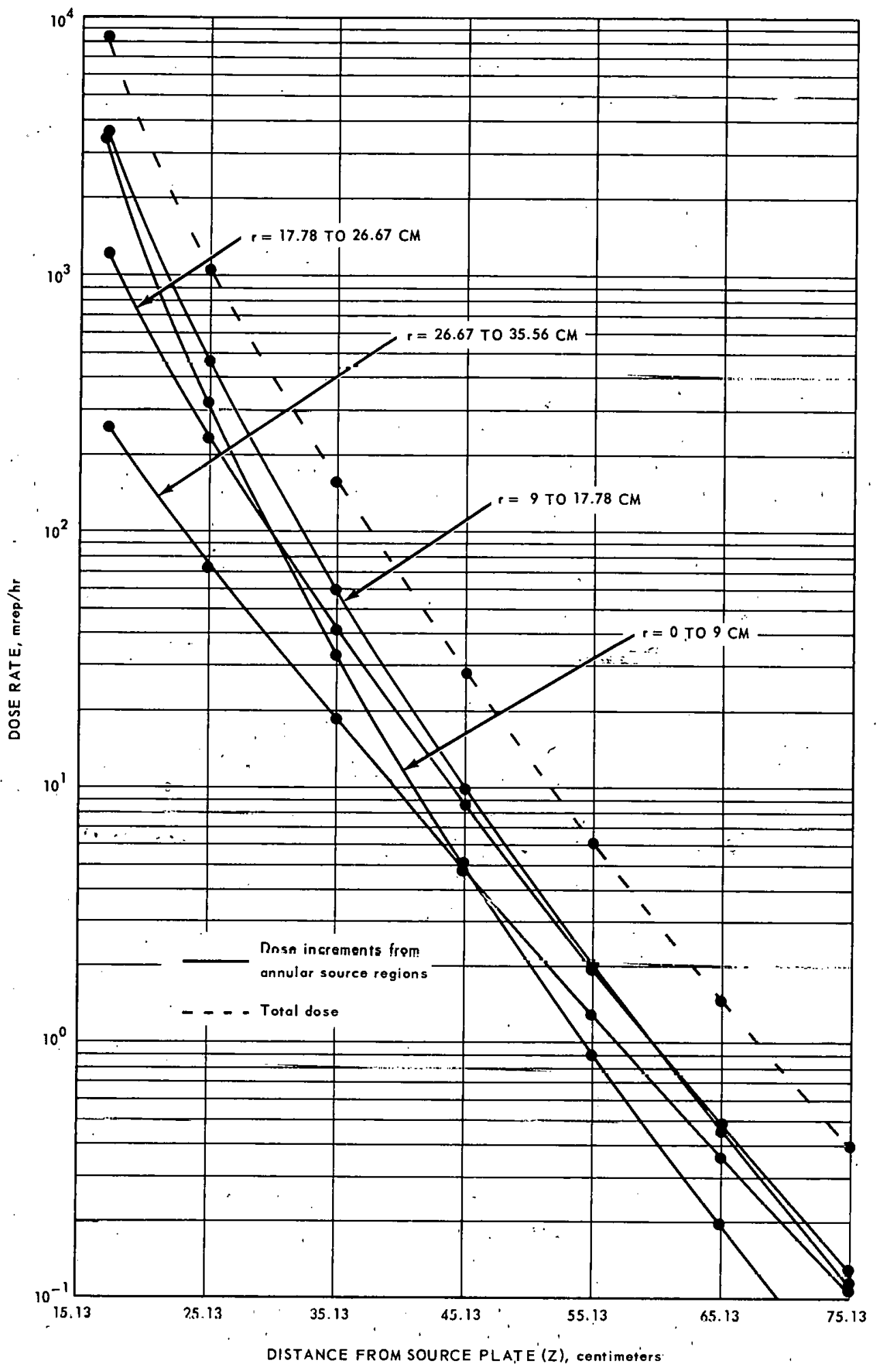

Fig. 13 - Centerline neutron dose rate from individual annular regions with iron pluginserted 


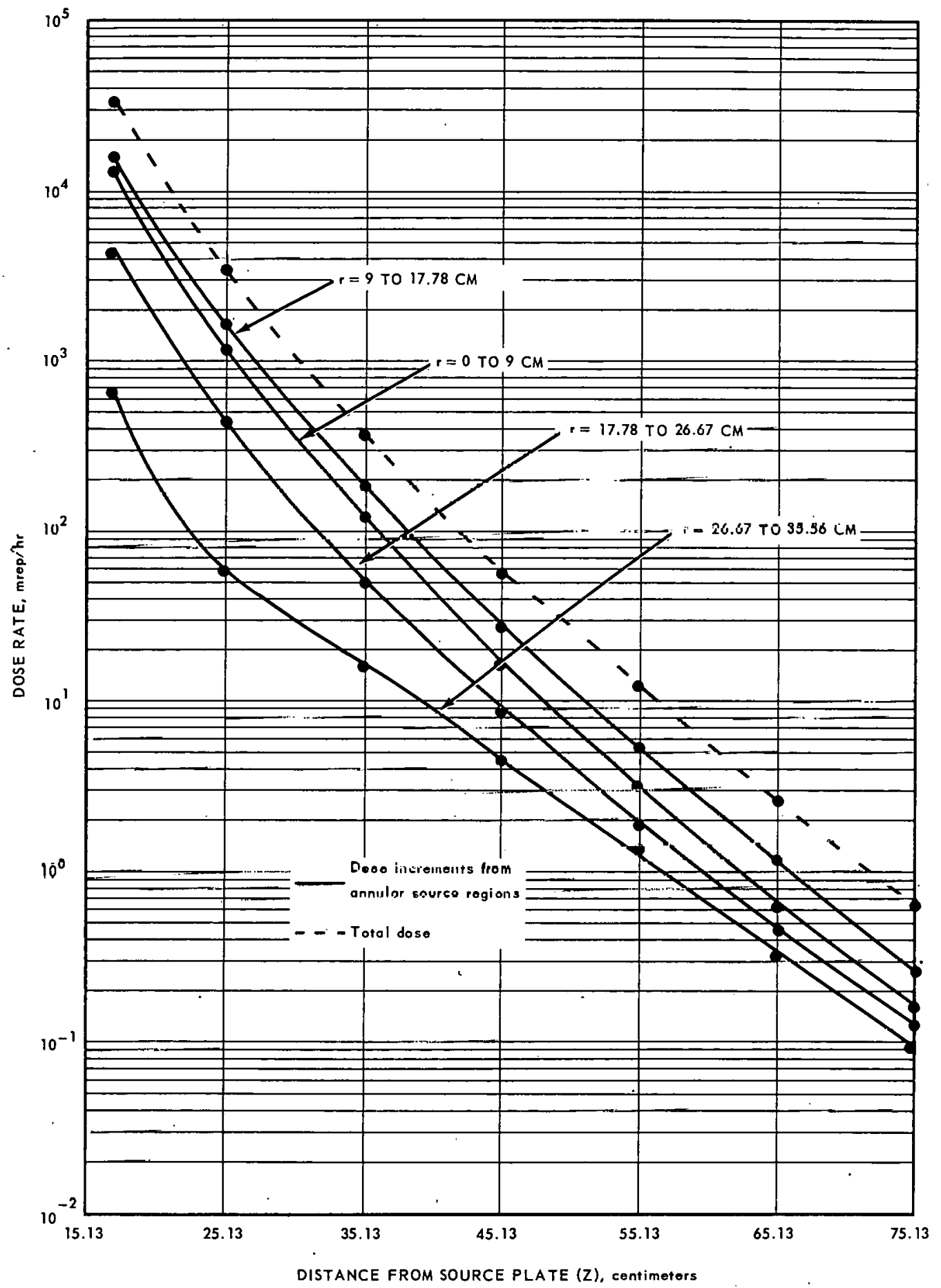

Fig. 14 - Centerline neutron dose mete from individual aurulur reglons with aluminum plug inserted 


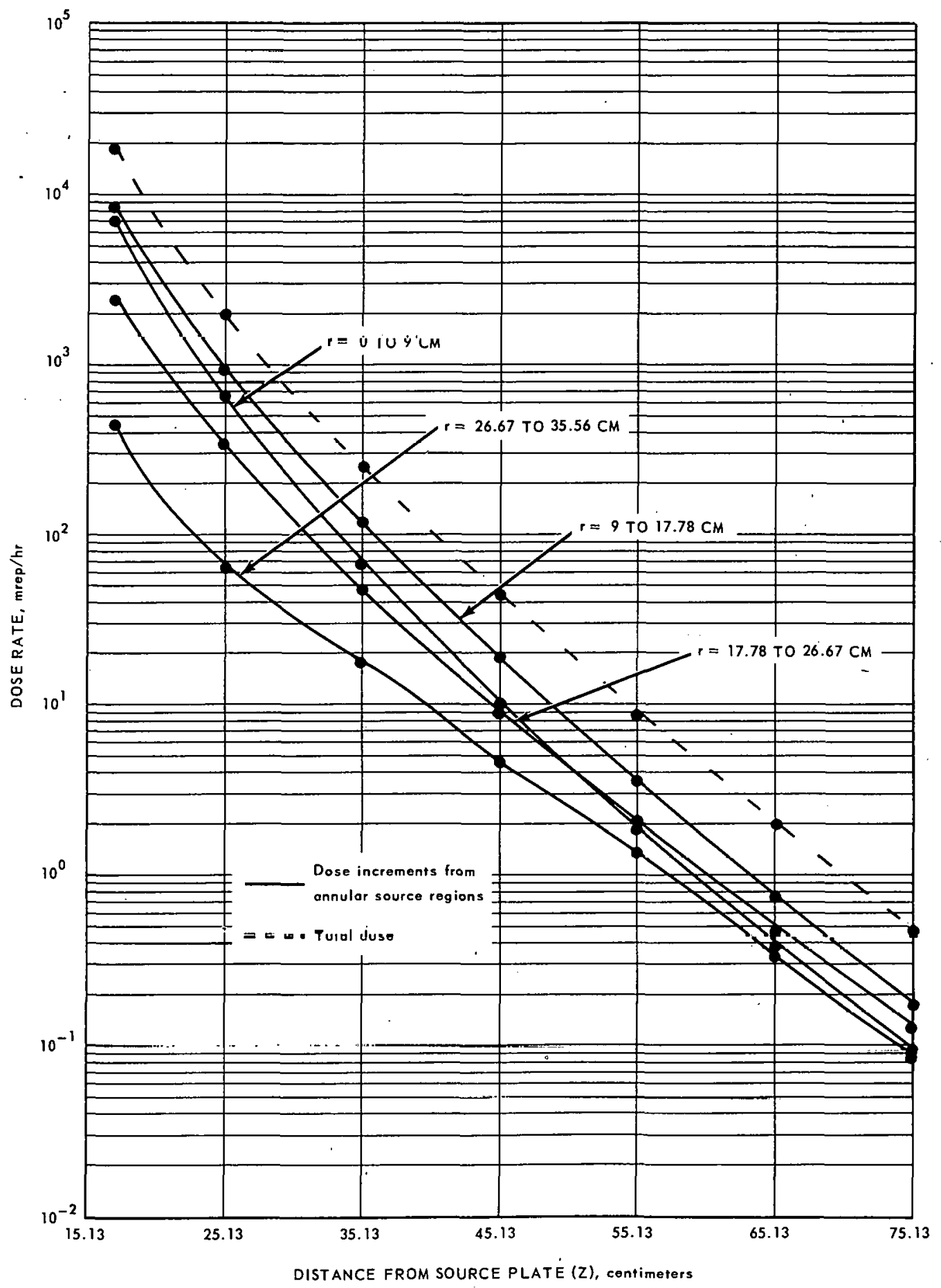

Fig. 15 - Centerline neutron dose rote from individual annular regions with lead plug inserted 


\section{Conclusions}

A dose rate ratio may be employed as a measure of the variation in dose rate at a fixed point due to variation in size of the source plate. One useful ratio which may be constructed is the dose rate as a function of the source-plate radius, divided by the dose rate when the snurce plate has a maximum radius of 35.56 centimeters, the receiver point being fixed in location. Such a gamma-ray dose-rate ratio as a function of source-plate radius, behind the iron plug, is given in Figure 16 for seven receiver points. The fast neutron dose rate ratio as a function of source-plate radius, again for the iron plug, is given in Figure 17 for seven receiver points.

For a fixed receiver point the average dose rate contribution per unit area was determined for each of the annular sections into which the source was divided. These values, plotted as a function of radius, give a histogram for each receiver point, as illustrated by Figure 18 (for gamma rays) and Figure 19 (for fast neutrons) behind the iron plug in the iron slab.

The computations indicate that the size of the disk source has a great influence on gamma dose rates beyond slabs of heavy material in water, whereas fast neutron dose rates are not affected as much by the size of the source plate. The effects studied here are due to geometry and source-plate size only, since the calculations do not include the effects of secondary gamma rays. 


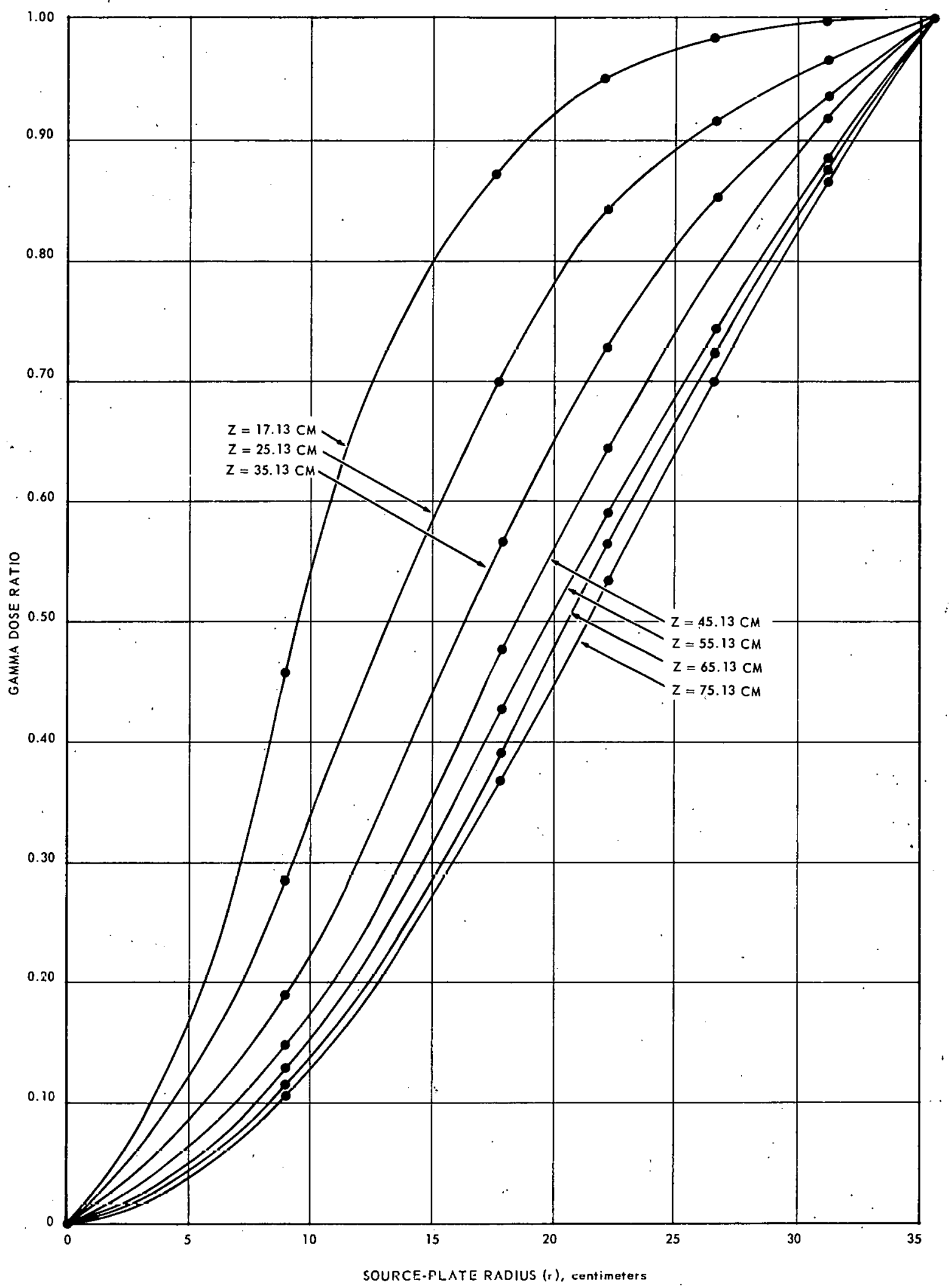

Fig. 16-Plot of the ratio, ganmo dose rate for source-plate radius $r$ over gamma dose rate for full source plate, as a function of $r$ for several receiverpoint distances (solid iron slab) 


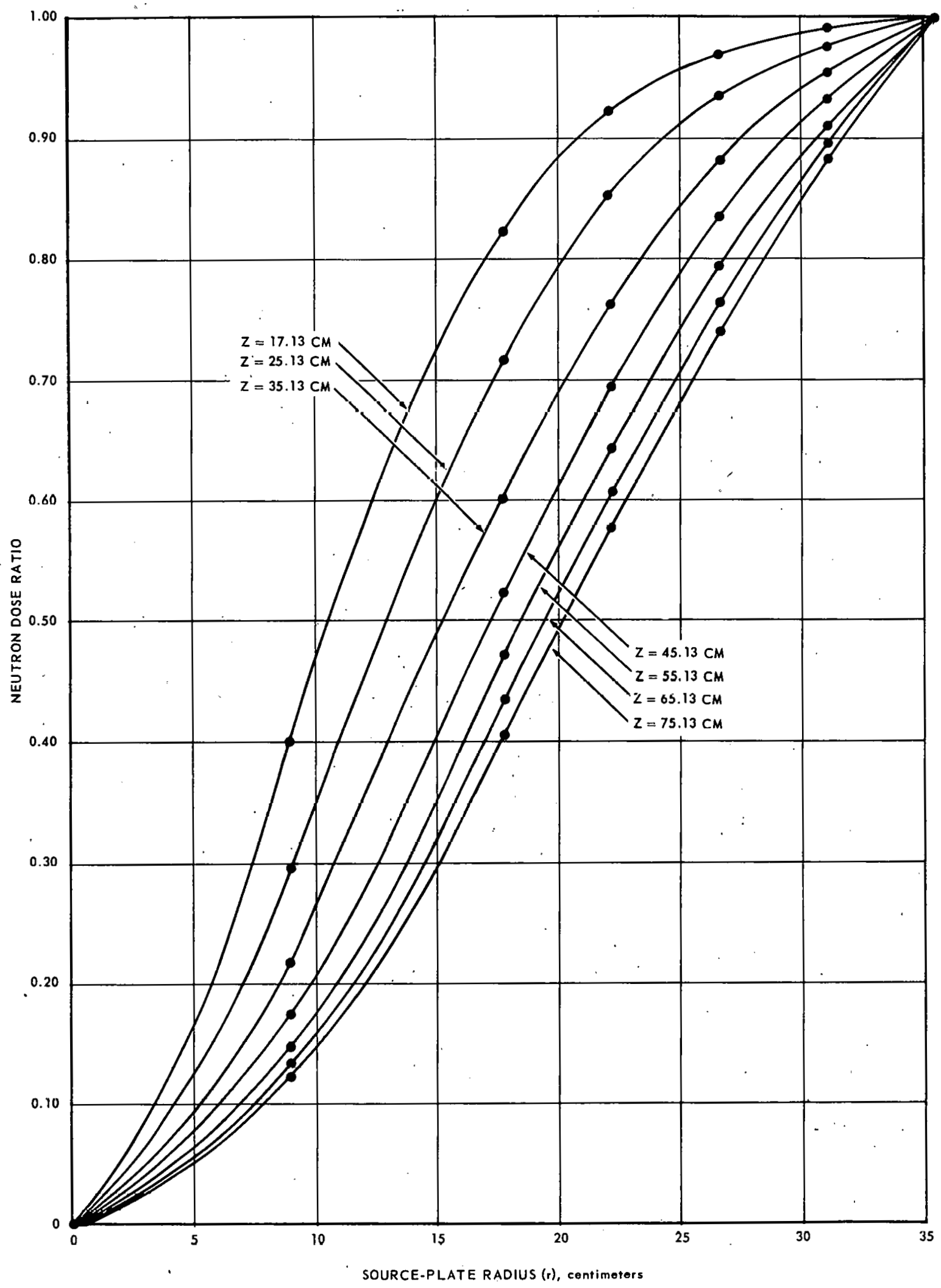

Fig. 17 - Plat of the ratio, neutron dose rate for a source plate of radius $r$ over neutron dose rate for full source plate, as a function of $r$ for several receiver-point distances (solid iron slab) 


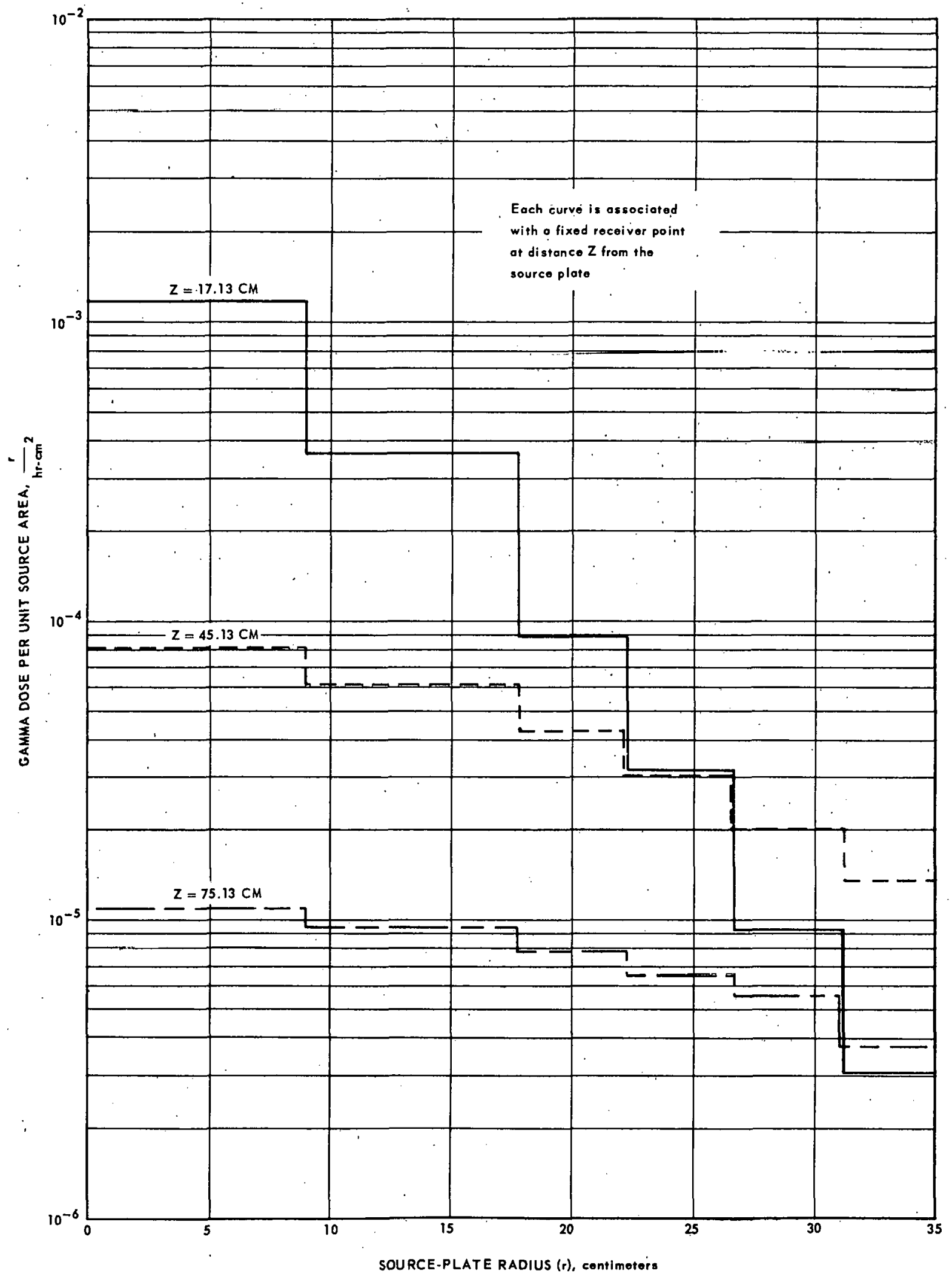

Fig. 18-Averoge gammo dose contributions per square centimeter from annular source regions (solid iron slab) 


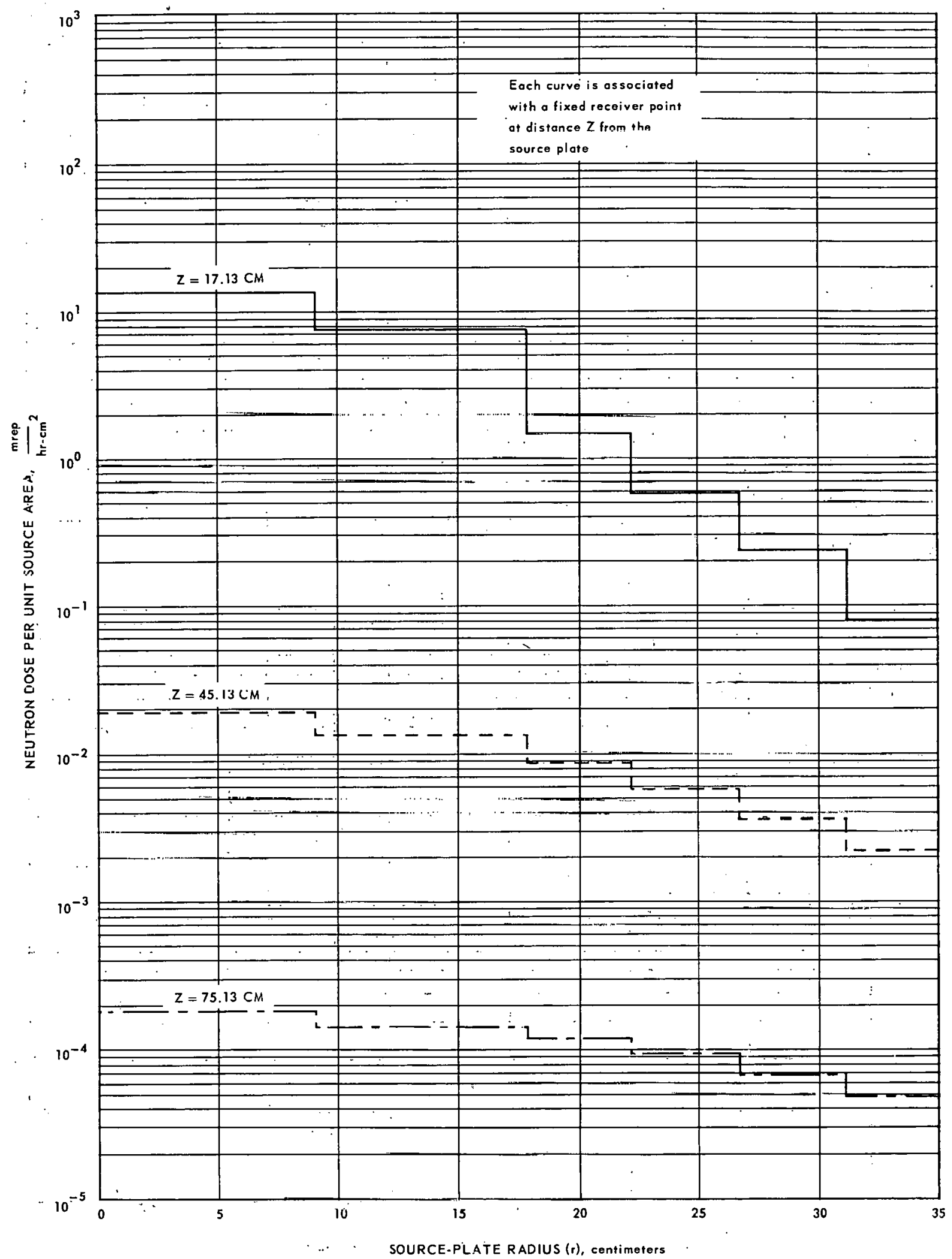

Fig. 19 - Average neutron dose contributions per square.centimeter from annular source regions ( solid iron slab) 


\section{References}

1. Morgan, W. R., Epstein, H. M., Anno, J. N., and Chastain, J. W., "Shielding-Research Area at Battelle," Battelle Memorial Institute, BMI-1291, Septembcr 18, 1958.

2. Goldstein, Herbert, "The Attenuation of Gamma Rays and Neutrons in Reactor Shields," Superintendent of Documents, U.S. Government Printing Office, Washington 25, D. C., May 1, 1957, pp. $74-85$.

3. Capo, M. A., Edwards, W. E., Loechler, J. J., and Paine, K. A., "Shielding Computer Program 04-4, Reactor Shield Analysis," General Electric Company, Aircraft Nuclear Propulsion Department, XDC 59-7-150, July 22, 1959. 